\section{An Illustration of Biological Nitrogen Fixation for Plant Science Students}

\author{
William R. Graves ${ }^{1}$ and
}

Lorna C. Wilkins ${ }^{2}$

\begin{abstract}
Additional index words. education, plant nutrition, Robinia pseudoacacia L., Glycine max Merill, black locust, soybean
\end{abstract}

Summary. A laboratory exercise for illustrating aspects of biological nitrogen fixation (BNP) to students in plant science courses is described. Surface-sterilized seeds of black locust (Robinia pseudoacacia L.) and soybean (Glycine max Merill) were sown together in plastic containers filled with a sterile, soilless medium. Containers were assigned randomly to treatments designed to show how inoculation with two strains of rhizobial bacteria and application of nitrate affect root nodulation and plant growth. Results demonstrated that BNF occurs in diverse legumes, that legumes vary in the strains of rhizobia with which they associate, that nodulation is inhibited by nitrate, and that dependency on BNP can reduce growth compared with plants provided nitrate.

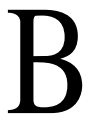
iological nitrogen fixation (BNF) by legumes is an important topic discussed in many plant science courses. A laboratory exercise we developed illustrates several aspects of BNF in an annual field crop and in a woody perennial. The objectives of this exercise were to demonstrate $\mathrm{BNF}$ in two diverse legumes, to illustrate specificity between host plants and rhizobial bacteria, to show the effect of nitrate application on root nodulation, and to compare

${ }^{1}$ Department of Horticulture, Iowa State University, Ames, IA 50011-1100.

${ }^{2}$ Department of Horticulture, University of Maryland, College Park, MD 20742-5611.

Published as journal paper no. 100, College of Agriculture, Iowa State Univ., Ames. the growth of plants provided nitrate with growth of plants dependent on BNF.

Students were provided seeds of soybean and black locust. Seeds of black locust must be scarified in $18 \mathrm{M}$ sulfuric acid for $60 \mathrm{~min}$ before or during the laboratory session. Working surfaces were sprayed with $10 \% \mathrm{NaOCl}$ $(\mathrm{v} / \mathrm{v})$, and hands and tools were sprayed with $70 \%$ ethanol between subsequent procedures. Students filled 36 new plastic containers $(15-\mathrm{cm}$ wide, $12-\mathrm{cm}$ high) with Jiffy Mix (Jiffy Products, West Chicago, Ill.). Other sterilized media low in $\mathrm{N}$ also would be suitable. Metal spatulas were used to create two 2-cm-deep holes in the root medium on opposite sides of the containers. Students placed three seeds ofsoybean in one hole and three seeds of black locust in the other. The seeds were surface-sterilized in $10 \% \mathrm{NaOCl}(\mathrm{v} / \mathrm{v})$ and rinsed three times in tap water immediately before sowing. Six containers were assigned randomly to each of six treatments (Table 1), and the outer surface of each container was labeled accordingly. Containers then were irrigated to container capacity with tap water and placed on a greenhouse bench, These procedures required $\approx 90 \mathrm{~min}$ of a laboratory session. During the next week, additional water was applied to the containers when the surface of the root medium appeared dry.

Liquid cultures of two rhizobial strains were prepared for the next weekly laboratory session. A Bradyrhizobium culture was created by inoculating a flask containing $50 \mathrm{ml}$ of modified arabinose-gluconate medium (MAG) (van Berkum, 1990) with USDA 97, which nodulates soybean (Keyser and Griffin, 1987). A flask of $50 \mathrm{ml}$ of MAG medium for the Rhizobium culture was inoculated with USDA 4249, which nodulates black locust (Batzli et al., 1992). Both strains were obtained from the USDA Rhizobium Collection (USDA/AR\& Soybean and Alfalfa Research Lab., Beltsville, Md.). Inoculated flasks were held in an environmental shaker at $28 \mathrm{C}$ and $100 \mathrm{rpm}$. Inoculations were done 3 and 5 days in advance for the Rhizobium and Bradyrhizobium cultures, respectively, because of differences in the growth rates of the strains. This allowed each culture to reach a density of $\approx 108$ cells $/ \mathrm{ml}$. Rhizobial inoculants for both species can be purchased
(LiphaTech, Milwaukee, Wis.); their use might simplify the exercise where facilities for bacterial culture are limited.

During $\approx 60 \mathrm{~min}$ of a laboratory session a week after seeds were sown, seedlings were thinned to one of both species per container by excision of shoots of extra seedlings near the surface of the root medium. Containers assigned to treatments $\mathrm{A}, \mathrm{B}, \mathrm{D}$, and $\mathrm{E}$ were inoculated with rhizobia (Table 1). A 1-ml sample of inoculum was dribbled on the surface of the root medium near the hypocotyl of each of the two seedlings in each container in these treatments (total of $2 \mathrm{ml}$ of inoculum per container) using individual sterile pipets. All containers then were irrigated to container capacity with either a half-strength Hoagland's solution \#l or a half-strength solution without N (Table 1). Both solutions were prepared after Hoagland and Arnon (1950), and Fe-EDTA was used as the iron source. Containers were irrigated as needed for the next 7 weeks. Solutions were applied cautiously to minimize splashing that could have transferred inoculum between containers. Upon harvest, root systems were removed from the containers and cleaned gently, and the number of nodules on each plant was counted. The stem length and the number of leaves for each plant also were measured. About $90 \mathrm{~min}$ of a laboratory session was required to complete the harvest. Analysis of variance was performed within species, and means were separated by using the StudentNewman-Keuls test $(P=0.05)$.

The number of nodules on soybean was greatest for plants in treatment A, which were inoculated with Bradyrhizobium and irrigated with minus-N solution (Table 1). Plants of soybeans in treatment $\mathrm{D}$, which were inoculated with Bradyrhizobium and irrigated with solution that contained nitrate, had $\approx 50 \%$ fewer nodules than plants in treatment $\mathrm{A}$ and had more than four times more nodules than plants in treatments $\mathrm{B}, \mathrm{C}, \mathrm{E}$, and $\mathrm{F}$ (Table 1). However, plants ofsoybean in treatment $\mathrm{D}$ had a greater number of leaves than those in treatment $\mathrm{A}$ Plants of black locust inoculated with Rhizobium and irrigated with minus$\mathrm{N}$ solution (treatment $\mathrm{B}$ ) had the greatest number ofnodules, and there were no differences in leaf number among black locust (Table 1). Stem length of 
Table 1. Rhizobial and nitrate treatment effects on nodulation and leaf number of seedlings of soybean and black locust.

\begin{tabular}{|c|c|c|c|c|c|c|c|}
\hline \multirow[b]{2}{*}{ Treatment } & \multicolumn{2}{|c|}{ Inoculun applied } & \multirow{2}{*}{$\begin{array}{c}\text { Nitrate } \\
\text { provided }\end{array}$} & \multicolumn{2}{|c|}{ Nodules/plant } & \multicolumn{2}{|c|}{ Leaves/plant } \\
\hline & Bradyrbizobium & Rhizobium & & Soybean & Black locust & Soybean & Black locust \\
\hline A & + & - & - & $158 a^{z}$ & $5 \mathrm{~b}$ & $10 b-d$ & $4 \mathrm{a}$ \\
\hline B & - & + & - & $18 c$ & $34 \mathrm{a}$ & $8 \mathrm{~cd}$ & $7 \mathrm{a}$ \\
\hline C & - & - & - & $19 c$ & $1 \mathrm{~b}$ & $7 \mathrm{~d}$ & $5 a$ \\
\hline $\mathrm{D}$ & + & - & + & $79 \mathrm{~b}$ & $3 b$ & $15 \mathrm{a}$ & $7 a$ \\
\hline $\mathrm{E}$ & - & + & + & $3 \mathrm{c}$ & $8 \mathrm{~b}$ & $14 \mathrm{ab}$ & $6 a$ \\
\hline F & - & - & + & $2 c$ & $1 \mathrm{~b}$ & $12 a-c$ & $7 \mathrm{a}$ \\
\hline
\end{tabular}

$\overline{{ }^{z} \text { Values are means of six replicates. Mean separation within columns is according to the Student- }}$ Newman-Keuls test $(\mathrm{P}=0.05)$.

both species was not affected by treatment (data not presented). Leaves of soybeans from treatments $\mathrm{B}$ and $\mathrm{C}$ were chlorotic at harvest.

These results demonstrate several important principles of BNF in legumes. First, they show that nodulation occurs in diverse species, which is important because plant science courses often do not discuss occurrence of BNF in woody plants. A second concept demonstrated by this exercise was that legumes require specific strains of rhizobia to nodulate. The Bradyrhizobium strain used in treatments $\mathrm{A}$ and D caused a large number ofnodules to form on the roots of soybean, but it was ineffective on black locust (Table 1). Similarly, the Rhizobium strain was effective on black locust, but not on soybean. The nodules that formed on soybean in treatments $\mathrm{B}$ and $\mathrm{E}$, and those on black locust in treatments $\mathrm{A}$ and $\mathrm{D}$, probably resulted from contamination, because the number of nodules was similar in uninoculated plants irrigated with minus- $\mathrm{N}$ solution
(Table 1). The effects of nitrate on nodulation and plant growth also are demonstrated by using this exercise. Nitrate partially inhibited nodulation in both species (Table 1). Despite greater nodulation, Bradyrhizobiuminoculated soybeans had fewer leaves when irrigated with minus-N solution (Table 1), which might be explained by the metabolic energy required for BNF.

We suggest a few modifications that might improve this exercise. It appeared that the growth rate of black locust was lower than that of soybean. This might explain the similarity in leaf number of black locust across all treatments. To account for apparent differences in the growth rate, seedlings of black locust could be planted at the same time that seeds of soybean are sown. In addition, a longer growth period and a different measure of plant growth, such as dry mass, could be used. Both of these changes might strengthen the demonstration of treatment effects on plant growth. Another possible alteration to this exercise would be to include in the containers a leguminous species that does not nodulate. Honey locust (Gleditsia triacanthos L.), redbud (Cercis canadensis L.), Kentucky coffeetree [Gymnocladus dioica (L.) C. Koch], and American yellowwood [Cladrastis kentukea (Dum.-Cours.) Rudd] are such species (Allen and Allen, 1981; Graves and van de Poll, 1992). Seeds of these legumes are readily available and easy to germinate, and their inclusion should demonstrate that not all legumes fix $\mathrm{N}$,.

\section{Literature Cited}

Allen, O.N. and E.K. Allen. 1981. The Leguminosae. Univ. of Wisconsin Press, Madison.

Batzli, J.M., W.R. Graves, and P. van Berkum. 1992. Diversity among rhizobia effective on Robinia pseudoacacia L. Applied Environ. Microbiol. 58:2137-2143.

Graves, W.R. and W. van de Poll. 1992. Further evidence that Cladrastis kentukea (Dum:Cours.) Rudd does not fix nitrogen with rhizobia. HortScience 27:1137.

Hoagland, D.R. and D.I. Arnon. 1950. The water-culture method for growing plants without soil. Calif. Agr. Expt. Sta. Circ. 347. (rev.).

Keyser, H.H. and R.F. Griffin. 1987. Beltsville Rhizobium culture collection catalog. USDA/ARS, Washmgton, D.C. ARS60 .

van Berkum, P. 1990. Evidence for a third uptake hydrogenase phenotype among soybean bradyrhizobia. Applied Environ. Microbiol. 56:3835-3841. 